\title{
Giant thoracoabdominal aortic aneurysm after endovascular repair
}

\section{Calin Pop ${ }^{1}, 2$, Sabin Nemes Bota ${ }^{1}$ \\ ${ }^{1}$ Cardiology Department, Emergency Clinical County Hospital, Baia Mare, Romania \\ ${ }^{2}$ Radiology Department, Faculty of Medicine, "Vasile Goldis" University, Arad, Romania}

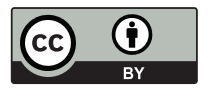

Received: 2020-05-03

Accepted: 2020-05-15

UDC: 618.1

\section{J Clin Med Kaz 2020; 3(57):53-54}

Corresponding Author: Ass. Pr. Calin Pop, MD, $\mathrm{PhD}$, Cardiology Department, Emergency Clinical County Hospital of Baia Mare, George Cosbuc Street nr 31, Baia Mare 430110, Romania.

Tel.: 0040744515794

E-mail:medicbm@yahoo.com

\section{Abstract}

Endoleak defined as residual blood flow in the "aneurysm sac" is the most frequent complication and occurs in 10 to $44 \%$ of all patients after endovascular repair of abdominal aortic aneurysms. Based on the origin of the blood flow to the aneurysm sac there are 4 types: those with at less $10 \mathrm{~mm}$ progression per year thought to be at risk of rupture and mandates correction. Screening for endoleaks is usually performed with CT or MR angiography. Endoleaks treatment is a real clinical challenge and until solutions are found, endovascular repair will remain an imperfect long-term treatment and continued follow-up will be mandatory.

Key words: abdominal aortic aneurysms, endovascular repair, endoleaks

\section{ЭНДОВАСКУЛЯРЛЫҚ ҚАЛПЫНА КЕЛТІРУДЕН КЕЙІНГІ ҮЛКЕН ТОРАКОАБДОМИНАЛДЫ АОРТА}

АНЕВРИЗМАСЫ

\section{К. Поп, ${ }^{2}$, С.Н. Бота}

'Кардиология бөлімшесі, Жедел медициналық жәрдем ауруханасы, Бая-Маре, Румыния

${ }^{2}$ Радиология кафедрасы, Медицина факультеті, Василе Голдиш Университеті, Арад, Румыния

\section{ТҰЖЫРЫМДАМА}

«Аневризмалық қапта» қалдық қан ретінде анықталған эндо қан кету - бұл ең көп кездесетін асқыну және іштің аорта аневризмасын эндоваскулярлық қалпына келтіруден кейін барлық пациенттердің 10-44\% -ында кездеседі. Аневризмалық қапқа қан ағымының басталуына байланысты 4 түрі бар; Прогресі жылына 10 мм-ден аз адамдар жыртылу және мандатты түзету қаупі бар деп саналады. Эндо қан кетудің скринингі әдетте компьютерлік томография немесе магнитті-резонанстық ангиография көмегімен жасалады. Эндо қан кетуді емдеу нақты клиникалық мәселе болып табылады, және шешімдер табылғанға дейін эндоваскулярлық жөндеу жетілдірілмеген ұзақ мерзімді емдеу болып қала береді және бақылаудан өту қажет болады.

Негізгі сөздер: іш қуысы аорта аневризмасы, эндоваскулярлық қалпына келтіру, эндо қан кету

\section{ГИГАНТСКАЯ ТОРАКОАБДОМИНАЛЬНАЯ АНЕВРИЗМА АОРТЫ ПОСЛЕ ЭНДОВАСКУЛЯРНОЙ РЕПАРАЦИИ}

\section{К. Поп, ${ }^{2}$, С.Н. Бота}

'Отделение кардиологии, Больница скорой медицинской помощи, Бая-Маре, Румыниия

${ }^{2}$ Кафедра радиологии, Факультет медицины Университет Василе Голдиш, Арад, Румыниия

\section{PEЗЮMЕ}

Эндоподтекание, определяемое как резидуальный кровоток в «аневризматическом мешке», является наиболее частым осложнением и встречается у 10-44\% всех пациентов после эндоваскулярной репарации аневризмы брюшной аорты. В зависимости от начала кровотока к аневризматическому мешку, существует 4 типа; те, у которых прогрессия менее 10мм в год, как считается, подвержены риску разрыва и коррекции мандатов. Скрининг на эндоподтекание обычно проводится с помощью компьютерной томографии или магнитно-резонансной ангиографии. Лечение эндоподтекания является реальной клинической проблемой, и до тех пор, пока решения не будут найдены, эндоваскулярная репарация останется несовершенным долгосрочным лечением, и продолжение наблюдения будет обязательным.

Ключевые слова: аневризма брюшной аорты, эндоваскулярная репарация, эндоподтекание 
A 69-year-old male, asymptomatic, lost of follow-up, presents 3 years after endovascular repair (EVAR) for a $50 \mathrm{~mm}$ diameter and $70 \mathrm{~mm}$ long thoracoabdominal aortic aneurysm type III. At, that time he received 2 successive multilayer flow modulator (MFM) stents grafts of $40 / 100 \mathrm{~mm}$ and $45 / 100 \mathrm{~mm}$. Images from $\mathrm{CT}$ angiography demonstrate contrast material outside the stent lumen indicating persistent endoleak and partial thrombosis of a huge aneurysm sac $92 \mathrm{~mm}$ diameter and $142 \mathrm{~mm}$ long (Figure A and B). Reconstructed CT show perigraft blood flow caused by an endoleak type II a (most probably inferior mesenteric arteries-IMA) seen as a blush anterior to the aortic stent graft (Figure C and D). Our asymptomatic patient has a persistent endoleak partially seal by thrombosis, but also an important enlargement (progression more than $10 \mathrm{~mm} /$ year) that may lead in our opinion to aneurysm rupture. We propose first a percutaneous transarterial embolization with glue (60\% success in our series) by transbrachial or transfemoral access. Despite the knowledge that aneurysm rupture may occur our patient refuse any intervention.

The incidence of type II endoleaks after EVAR has been reported as between $10 \%$ and $44 \%$ [1]. A type II endoleak is attributed to retrograde flow from the IMA (IIa), lumbar arteries (IIb), or other collateral vessels. Current guidelines recommend intervention in type II endoleak when expansion of sac diameter $\geq 10 \mathrm{~mm} /$ year, detected during follow up using the same imaging modality (usually angio CT) and measurement method [2]. Unfortunately, optimal thresholds are not clear. Endovascular techniques are the preferred modality, but surgical repair remains the definitive option in cases where less invasive methods have failed or are precluded [3]. Endoleaks treatment is a real clinical
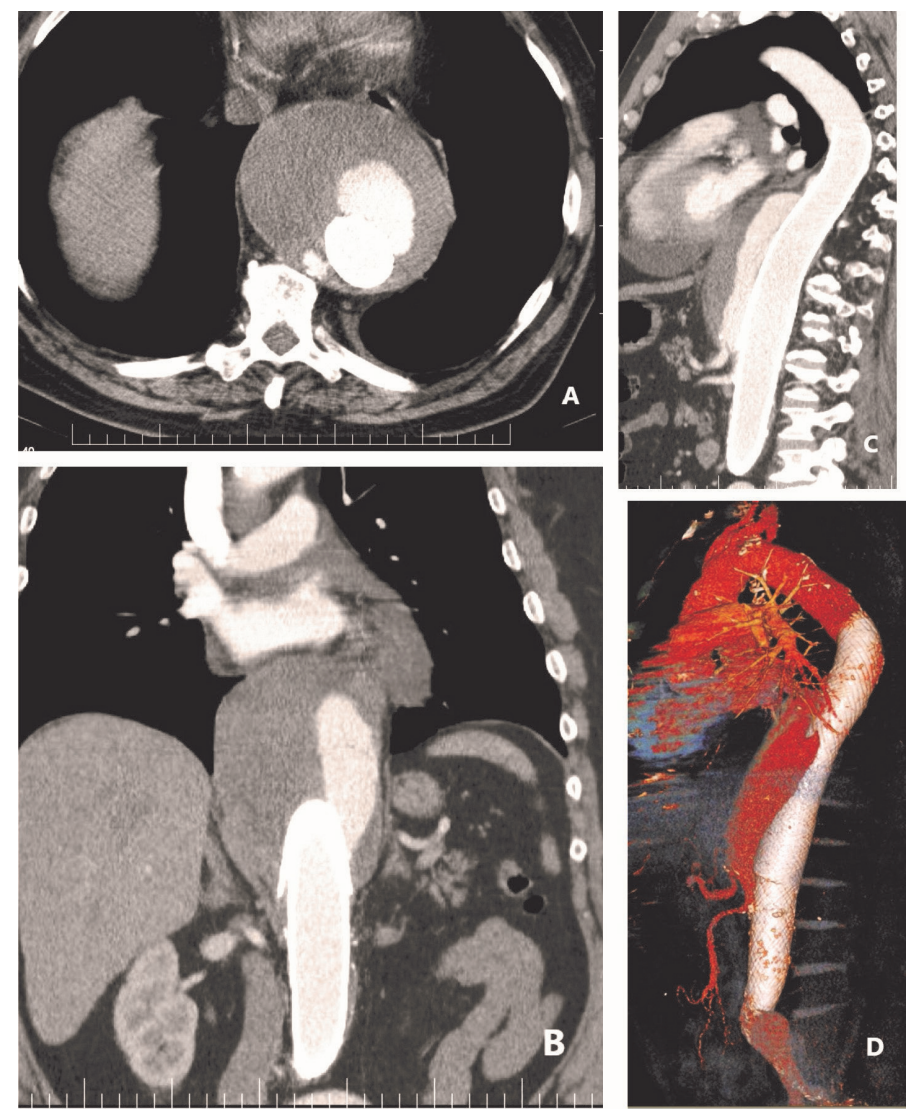

challenge and until solutions are found, EVAR will remain an imperfect long-term treatment and continued follow-up will be mandatory.

Disclosures: There is no conflict of interest for all authors.

\section{References}

1. Gelfand DV, White GH, Wilson SE. Clinical significance of type II endoleak after endovascular repair of abdominal aortic aneurysm. Ann Vasc Surg. 2006; 20(1):69-74. https://doi.org/10.1007/s10016-005-9382-z

2. Wanhainen A, et al. European Society for Vascular Surgery (ESVS) 2019 Clinical Practice Guidelines on the Management of Abdominal Aorto-iliac Artery Aneurysms. European Journal of Vascular and Endovascular Surgery. 2019; 57(1):8-93. https://doi. org/10.1016/j.ejvs.2018.09.020

3. Chen, J., Stavropoulos, S. W. Management of Endoleaks. Seminars in interventional radiology. 2015; 32(3):259-264. https://doi. org/10.1055/s-0035-1556825

How to cite this article: Calin Pop, Sabin Nemes Bota. Giant thoracoabdominal aortic aneurysm after endovascular repair. J Clin Med Kaz. 2020; 3(57):53-54 